\title{
Synthetic brain imaging on a spiking neural model of parieto-frontal interactions in reaching
}

\author{
James J Bonaiuto*1,2 and Michael A Arbib ${ }^{1,2,3}$
}

\author{
Address: ${ }^{1}$ Neuroscience, University of Southern California, Los Angeles, CA 90089, USA, ${ }^{2}$ USC Brain Project, University of Southern California, \\ Los Angeles, CA 90089, USA and ${ }^{3}$ Computer Science, University of Southern California, Los Angeles, CA 90089, USA \\ Email: James J Bonaiuto* - bonaiuto@usc.edu \\ * Corresponding author
}

from Eighteenth Annual Computational Neuroscience Meeting: CNS*2009

Berlin, Germany. 18-23 July 2009

Published: 13 July 2009

BMC Neuroscience 2009, I0(Suppl I):P82 doi:I0.1 I86/I47|-2202-I0-SI-P82

This abstract is available from: http://www.biomedcentral.com//47I-2202/I0/SI/P82

(c) 2009 Bonaiuto and Arbib; licensee BioMed Central Ltd.

\section{Introduction}

We developed a model of arm-reaching that uses spiking neural model arranged in dynamic neural fields to encode sensory input and perform reach target selection. The output of the model was used to control a simulated threedimensional arm and hand in a reciprocal reaching task based on one used in monkey neurophysiological literature. To perform synthetic brain imaging on our model, we have implemented the extended balloon model [1] with a capillary model extension [2]. This simulates blood flow in response to a flow-inducing signal, as well as blood volume, deoxyhemoglobin concentration, oxygen extraction rate and the BOLD response. To facilitate both region- and voxel-based analysis of simulated PET and fMRI responses, simulated neurons in each region are grouped into virtual voxels. Each virtual voxel contains an instantiation of the extended balloon model. The sum of the synaptic activity and transmembrane current magnitudes over all of the neurons in a voxel is used to generate the flow-inducing signal for the rCBF component. This system allows synthetic PET and fMRI signals to be generated simultaneously by sampling the rCBF or BOLD signals, respectively, according to the repetition time (TR) of the scan. The overall model is thus able to address behavioral, electrophysiological and neuroimaging data in both monkeys and humans.

\author{
References \\ I. Friston KJ, Mechelli A, Turner R, Price CJ: Nonlinear responses in \\ fMRI: the Balloon model, Volterra kernels, and other hemo- \\ dynamics. Neuroimage 2000, 12:466-477. \\ 2. Zheng Y, Martindale J, Johnston D, Jones M, Berwick J, Mayhew J: A \\ model of the hemodynamic response and oxygen delivery to \\ brain. Neuroimage 2002, 16:617-637.
}

